\title{
Detection of Respiratory Frequency in the Recordings of Electrocardiogram, Blood Pressure or Sympathetic Nerve Activity in the Conscious Rat
}

\author{
Tadashi NAKamura', Haruhisa Hirakawa², Yoshiaki Hayashida², \\ Yasuhide NAKASHIMA ${ }^{3}$ and Akio KUROIWA ${ }^{4}$ \\ 'Occupational Health Training Center, \\ ${ }^{2}$ Department of Systems Physiology, Institute of Industrial Ecological Sciences, \\ ${ }^{3}$ Second Department of Internal Medicine, School of Medicine, University of Occupational \\ and Environmental Health, Japan. Yahatanishi-ku, Kitakyushu 807, Japan \\ ${ }^{4}$ Moji Rosai Hospital. Moji-ku, Kitakyushu 801, Japan
}

Abstract: We extracted the respiratory frequency in conscious rats from variations of blood pressure, electrocardiogram, or renal sympathetic nerve activity by means of a band-pass filter. The frequency derived from any one of these parameters corresponded to directly recorded respiratory chest movements. The method may be useful when respiration and cardiovascular parameters have to be recorded in small animals during steady state when minimal surgical intervention is crucial.

Key words: respiratory frequency, band-pass filter.

(Received 10 May 1996, accepted 22 July 1996)

\section{Introduction}

Functions of the cardiovascular and respiratory systems are closely connected, and it is often desirable to know at least the respiratory frequency when cardiovascular responses during experimental procedures are analyzed. In non-anesthetized small animals, when surgical intervention has to be kept to a minimum, it is difficult to monitor respiration and cardiovascular variables at the same time. Implanted transducers may interfere with physiological functions. Ventilatory volume and frequency can be obtained by plethysmography of the animal kept in an air-tight box [1], or the respiratory frequency can be derived from changes in the electrical impedance of the chest. Plethysmography may, however, interfere with the set-up of the experiment, and electrodes or the DC current used to measure the impedance may disturb other recordings. In one study of human subjects, the authors attempted to derive the respiratory 
rate indirectly from changes in the electrical axis of the electrocardiogram (ECG) [2].

We here describe attempts to extract the respiratory waveform in conscious rats by means of a band-pass filter from blood pressure (BP), EGG, or sympathetic nerve activity (SNA); the results were compared with respiratory chest movements recorded directly by means of a respiratory pickup sensor [3].

\section{Materials and Methods}

Animal preparation

Male Wistar rats weighing 300-450 $\mathrm{g}$ from the Animal Center of the University were used in this experiment.

The recording methods and the equipment have been described in detail elsewhere [3]. Briefly, rats were anesthetized with pentobarbital sodium (50 $\mathrm{mg} / \mathrm{kg}$ ip), and the parietal part of the skull was covered with dental acrylic cement for the attachment of catheters and electrodes. After at least one week, the rats were re-anesthetized with pentobarbital sodium, and measuring devices were implanted under aseptic conditions. The BP was recorded by means of a heparin-filled polyethylene catheter attached to a blood pressure gauge and inserted into the femoral artery. The EGG was recorded through a pair of Teflon-coated stainless steel wires implanted under the skin of the mid-chest. SNA was recorded from a branch of the left renal nerve exposed through a left flank incision; the nerve was freed from surrounding tissue, and bipolar stainless-steel electrodes were held in place by a two-component silicone rubber gel (Wacker silicone 604, Wacker-Chemie, Munich, Germany). A respiratory pickup sensor (KU88-066 Unique Medical, Tokyo, Japan) was pulled through a channel under the skin along the chest. All catheters and electrode wires were tunneled subcutaneously to the neck and attached to the skull plate. Flexible lead wires and catheters were connected to a slip ring so that the rats could move, drink and eat freely. The rats were allowed to recover from anesthesia for at least 48 hrs under constant room temperature $\left(24^{\circ} \mathrm{C}\right)$. They were cared for throughout the experiment in accordance with the Guiding Principles for the Care and Use of Animals approved by the Council of the Physiological Society of Japan.

\section{Data recording}

BP, EGG, renal SNA and respiratory chest movements were continuously recorded in conscious rats from 2 to 7 days after the operation. The action potentials of the renal nerve were amplified and filtered $(50-1000 \mathrm{~Hz})$ by a differential low-noise amplifier (DC-10, Nihon Kohden, Tokyo, Japan). In order 
to obtain the "mean renal SNA", the rectified signal was integrated with a time constant of $0.1 \mathrm{~s}$ through a voltage integrator (EI-601G, Nihon Kohden). The analog outputs of BP, ECG, and renal SNA were recorded on a magnetic tape recorder (XR-30, TEAC, Tokyo, Japan) for later analysis.

Extraction of the respiratory frequency waveforms

We used either an analog band-pass filter (E-3201A, NF Electronic Instruments, Yokohama, Japan) or a digital band-pass filter (Finite impulse response type programmed by ourselves). The recorded signals were passed through the band-pass filter with the attenuation ratio of $1 / 3$ per octave. The center frequency was initially set around $1.4 \mathrm{~Hz}$, because the normal ventilatory frequency in the conscious rat ranges from 0.9 to $2.0 \mathrm{~Hz}(54-120$ times $/ \mathrm{min})$. Then, we searched manually for the optimal center frequency in order to obtain a smooth curve with the largest possible amplitude. When the respiratory frequency curve was extracted from the spike-like signal as ECG or as BP, it was necessary to use a narrower band-pass filter in order to steeply attenuate high frequencies, and to reduce the interposition of notches on the filtered waveform. Furthermore, Rwave- or S- wave-dominant EGGs had to be used for filtering.

Alternatively, the BP and EGG signals were converted from analog to digital signals at the sampling interval of $25 \mathrm{~Hz}$. The digitized data were passed through a finite-impulse-response type digital band-pass filter. The center frequency was set to about $1.4 \mathrm{~Hz}$, and the bandwidth was adjusted to obtain a smooth curve with maximum amplitude as in the case of the analog band-pass filter.

\section{Results}

Figure 1 shows typical recordings of $\mathrm{BP}, \mathrm{EGG}$, renal SNA (original and mean) and respiratory chest movements. The recordings of BP, EGG, original SNA and mean SNA show small oscillations coupled with the respiratory movements. Respiratory curves extracted from the BP signal, ECG signal or mean SNA by means of an analog band-pass filter together with the directly recorded respiratory movements are shown in Figure 2. The extracted curves closely resembled those that were directly recorded, but there was a small phase delay. The form of the band-passed curve became irregular, it decreased in amplitude and eventually disappeared to within noise level when the respiratory frequency changed. Nevertheless, a respiratory curve reappeared when the center frequency of the filter was re-adjusted (data not shown). We could follow the respiratory frequency in $\mathrm{BP}$ when the frequency was within $\pm 30 \%$ of the center frequency, in $\mathrm{ECG}, \pm 25 \%$ and in $\mathrm{SNA}, \pm 20 \%$ of the center frequency. 

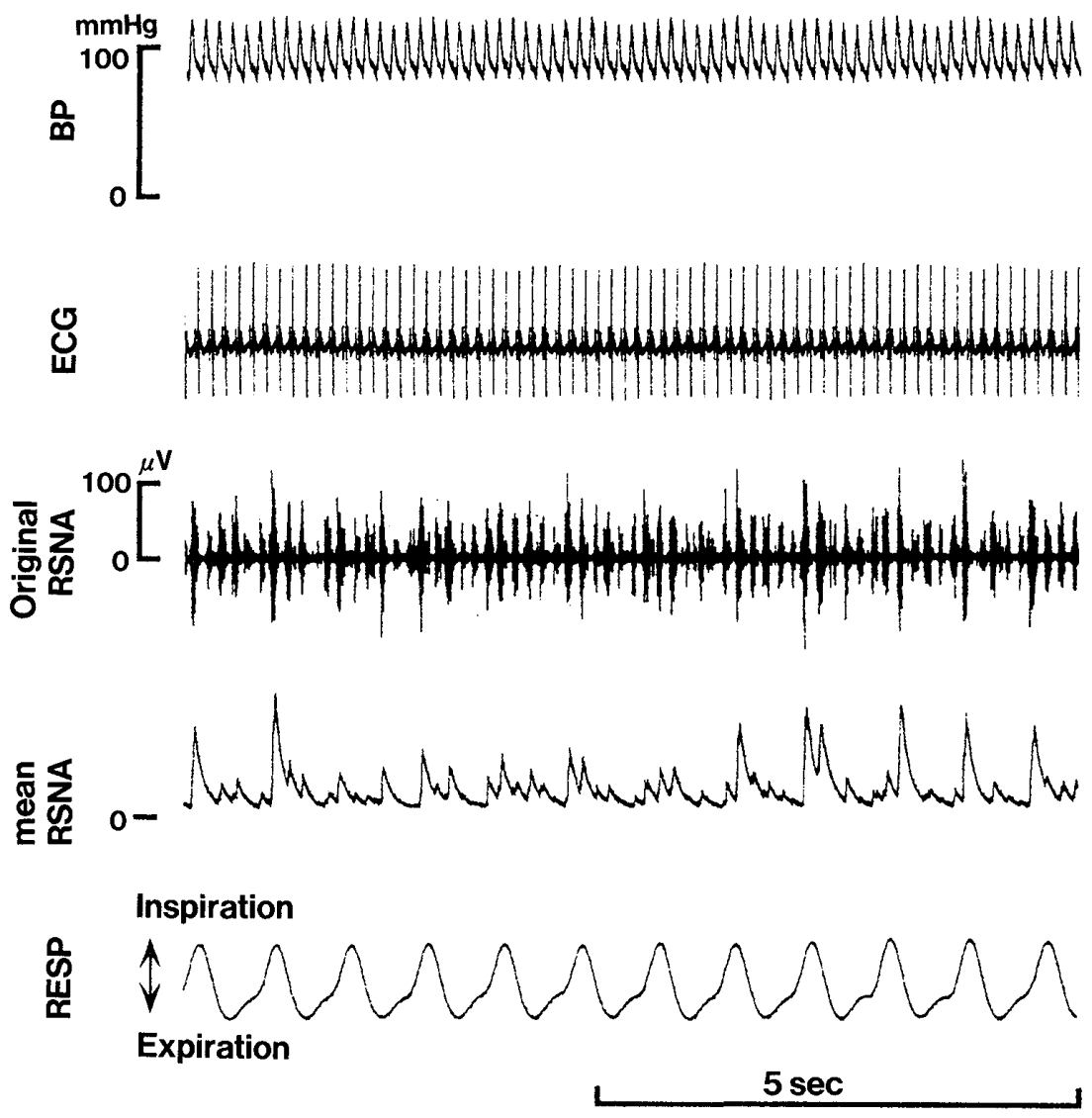

Fig. 1. Typical recordings of arterial blood pressure (BP), electrocardiogram (EGG), original renal sympathetic nerve activity (RSNA), integrated mean RSNA, and respiratory chest movements (RESP) in a conscious rat. Note small respiration-dependent oscillations of all parameters.

When the real frequency was outside of these ranges, the amplitudes of the respiratory frequency curve was decreased to the noise level.

Figure 3 shows the respiratory curve extracted from the BP signal by means of a digital band-pass filter. The respiratory fluctuation in the original BP curve is distinct. Interestingly, the directly recorded respiratory curve but not the band-passed respiratory curve was affected by movements of the rat.

\section{Discussion}

The present study demonstrates that respiratory curves in conscious rats can reliably be obtained from variations of BP, EGG and renal SNA by means of a bandpass filter and then be recorded either on-line or off-line. One drawback of the method is that the respiratory frequency cannot be determined during episodes of ventricular arrhythmia, gross body movements and during abrupt changes in 


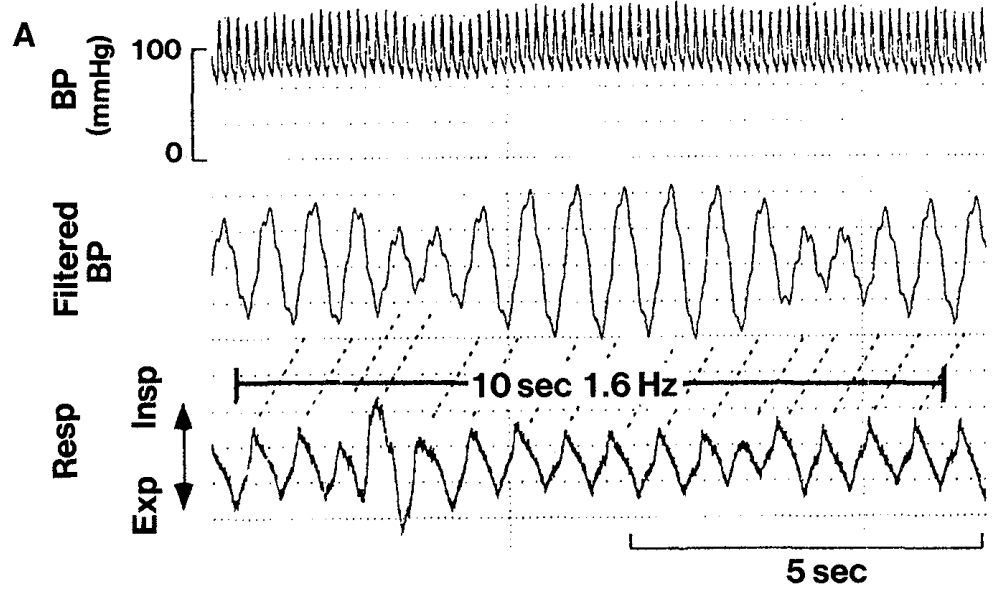

B

U্

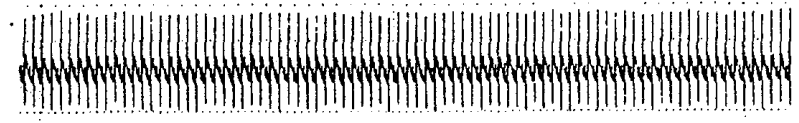

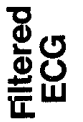
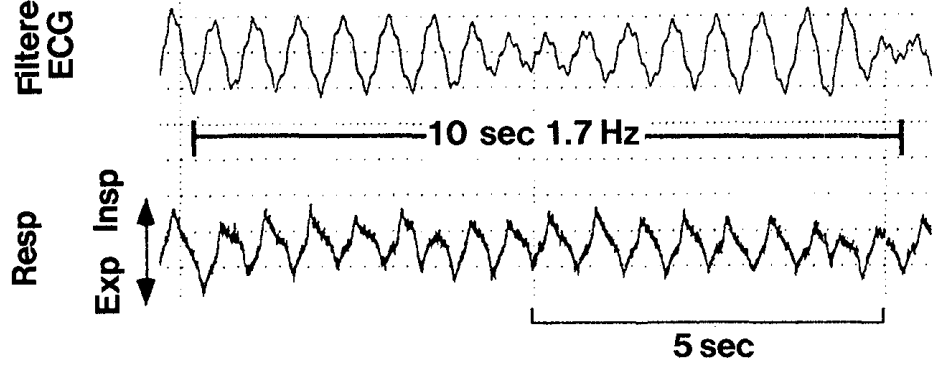

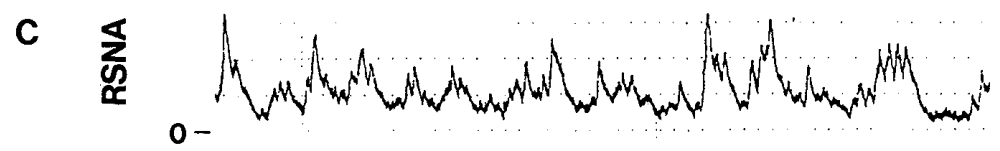
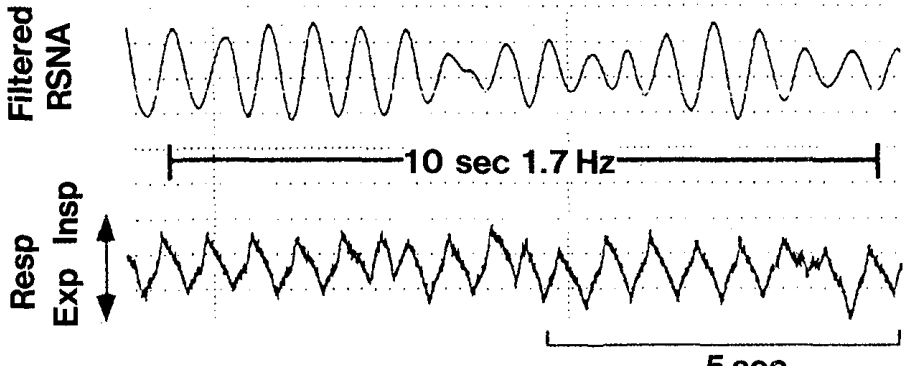

\section{$5 \mathrm{sec}$}

Fig. 2. Respiratory curves derived from blood pressure (BP) (A), electrocardiogram (ECG) (B) and renal sympathetic nerve activity (RSNA) (C) by means of an analog band-pass filter with a center frequency of $1.6 \mathrm{~Hz}$.

A Simultaneous recordings of original BP, band-passed BP curve (Filtered BP), and the chest movement picked up by a sensor (Resp). Note phase delay (dotted oblique line) of the filtered curve in relation to the respiratory chest movement. Insp; inspiration. Exp; expiration.

B From top to bottom: original EGG, band-passed EGG curve (Filtered EGG), and the chest movement (Resp). In this case, a low pass high cut filter was combined with the band pass filter to attenuate steeply the higher frequency.

C From top to bottom: original mean RSNA, band-passed mean RSNA (Filtered RSNA), and the chest movement (Resp). 


\section{Original

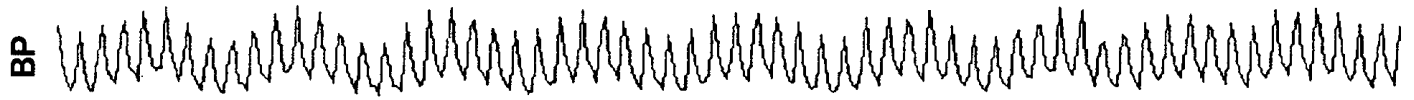
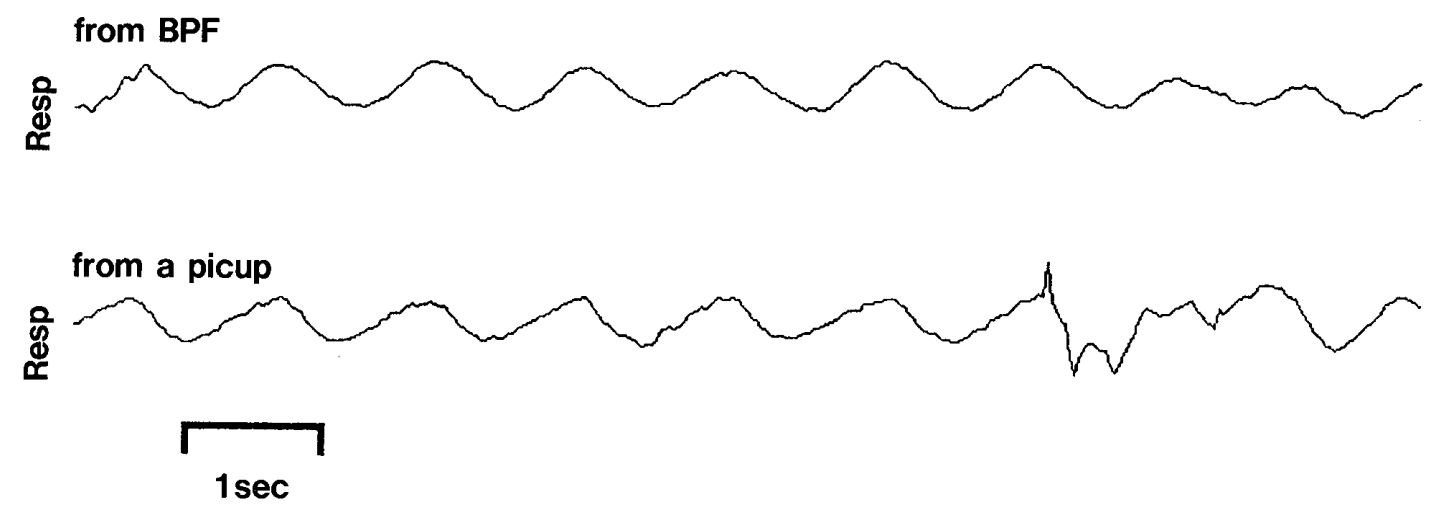

Fig. 3. Respiratory curve derived from the blood pressure (BP) by means of a digital-band pass filter (FIR type). From top to bottom: original BP, band-passed BP curve, and the chest movement picked up by a sensor (Resp). Note movement artifacts in the mechanogram but not in the filtered curve. Abbreviations, see Fig. 2.

respiratory frequency.

Every extracted respiratory curve showed a phase delay from the real one. One cause of the delay may be due to the circuit delay of the instrument, that is the lower the center frequency, the longer the delay. Another cause may be the delay in the effect of respiration on each parameter.

Respiratory oscillations of BP and heart rate are well known [4] and have been attributed to mechanical effects on intrathoracic vessels or to changes in stroke volume and cardiac cycle [4]. It has been demonstrated previously $[5,6,7,8]$ and was confirmed by the present study, that SNA fluctuates with the respiration. Several mechanisms have been proposed: the inflation reflex from the lung via vagal afferents [5], the baroreflex response to the respiratory oscillation of the arterial BP [6] and linkage between the respiratory center and the vasomotor center in the central nervous system [7]. Using the mean SNA in order to extract a respiratory curve poses practical problems. Respiratory dependent fluctuations of the SNA may be restricted to the renal nerve [8]; the renal SNA shows continuous rhythmic bursts synchronized with each cardiac cycle, whereas central respiratory drive and oscillation of SNA sometimes desynchronize [6]. Furthermore, it is crucial that SNA be recorded with a sufficiently high signal to noise ratio.

The origin of the respiratory oscillations of the EGG signal are unknown. They may be attributed to the change in amplitude of QRS complexes by the movements of the chest, i.e. to changes in the heart axis. In order to obtain good 
respiratory curves, it was necessary to use $\mathrm{R}$-wave- or $\mathrm{S}$ - wave-dominant EGGs and also a digital band-pass filter with a far higher sampling interval than $25 \mathrm{~Hz}$.

Further study will be necessary to develop an automatic extraction of the respiratory frequency using the digital filtering.

\section{Acknowledgments}

The authors thank Dr. Y. G. Lin (Univ. of Hawaii) for his informative advice and Dr. H. Schmalbruch (Univ. of Copenhagen) for his critical reading of the manuscript.

\section{References}

1. Coggins CRE, Duchosal F, Musy G \& Ventorone R (1981): Measurement of respiratory patterns in rodents using whole-body plethysmography and a pneumotachograph. Lab Anim 15: $137-140$

2. Pinciroli F, Rossi R, Vergani L, Carevali P, Mantero S \& Parigi O (1986) : Remarks and experiments on the construction of respiratory waveforms from electrocardiographic tracings. Comput Biomed Res 19:391-409

3. Nakamura T \& Hayashida Y (1992) : Autonomic cardiovascular responses to smoke exposure in conscious rats. Am J Physiol 262(Regul Integr Comp Physiol 31): R738-R745

4. Koepchen HP (1984): History of studies and concepts of blood pressure waves. In: Mechanisms of Blood-pressure Waves. Miyakawa K, Koepchen HP \& Plolsa C, ed.). Springer-Verlag, Berlin pp 3-23

5. Angell-James JE, Elsner R \& Daly M De B (1981): Lung inflation: effects on heart rate, respiration, and vagal afferent activity in seals. Am J Physiol 240(Heart Circ Physiol 9): H190-H198

6. Barman SM \& Gebber GL (1976) : Basis for synchronization of sympathetic and phrenic nerve discharges. Am J Physiol 231: 1601-1607

7. Eckberg DL, Kifle YT \& Roberts VL (1979): Phase relationship between normal human respiration and baroreflex responsiveness. J Physiol 304: 489-502

8. Ninomiya I, Nishimaru N \& Irisawa H (1971): Sympathetic nerve activity to the spleen, kidney, and heart in response to baroreceptor input. Am J Physiol 221: 1346-1351 
意識下ラットにおける心電図，血圧および交感神経活動からの 呼吸頻度の計測法

中村 正 ${ }^{1}$, 平川 晴久 ${ }^{2}$, 林田 嘉朗 ${ }^{2}$, 中島 康秀 ${ }^{3}$, 黑岩 昭夫 ${ }^{4}$ ${ }^{1}$ 産業医科大学産業医実務研修センター 産業医科大学産業生態科学研究所 応用生理学教室 噒業医科大学医学部第二内科学教室 4門司労災病院

要 旨： 意識下ラットの血圧，心電図あるいは腎臟交感神経活動からバンドパスフィルター を用いて呼吸頻度を導出した。これらのパラメーターから得られた呼吸頻度は, 胸 郭の呼吸運動の直接記録による結果と一致した，従ってこの方法は，定常状態の呼 吸数の計測が必要であるうえに，外科的侵襲を最小限に止めたい場合の動物実験に 有用な方法と考えられた。

J UOEH (産業医大誌), 18 ( 3 ): 177-184 (1996) 